\title{
TEORIA DO ENSINO DESENVOLVIMENTAL E A ORGANIZAÇÃO DO ENSINO DOS CONCEITOS DE ÁREA E DE PERÍMETRO NOS ANOS INICIAIS DO ENSINO FUNDAMENTAL
}

\author{
THEORY OF DEVELOPMENTAL TEACHING AND THE ORGANIZATION OF \\ TEACHING OF AREA AND THE PERIMETER CONCEPTS IN THE INITIAL YEARS \\ OF ELEMENTARY SCHOOL
}

\author{
iD Giselma Cecilia Serconek \\ Doutorado em Educação \\ Universidade Estadual de Maringá - UEM \\ Maringá, Paraná - Brasil \\ giselmaserconek@gmail.com \\ Marta Sueli de Faria Sforni \\ Pós-Doutorado em Educação \\ Universidade Estadual de Maringá - UEM \\ Maringá, Paraná - Brasil \\ martasforni@uol.com.br
}

\begin{abstract}
Resumo: No presente artigo é apresentada a trajetória de investigação de doutorado que teve como objeto a organização do ensino da Matemática. A questão eixo de nossa investigação traduziu-se em: quais as contribuições da Teoria do Ensino Desenvolvimental para a organização do ensino dos conceitos de área e de perímetro nos anos iniciais do Ensino Fundamental? As discussões fundamentam-se na Teoria do Ensino Desenvolvimental, que embasa o desenvolvimento de um experimento didático, com a proposição de uma tarefa de estudo, e a análise dos seus resultados. A análise do experimento delineia o percurso formativo das capacidades de análise, planejamento e reflexão, componentes do pensamento teórico. Constatou-se, na análise do experimento, que o pensamento em nível teórico pode ser engendrado por meio da tarefa de estudo, quando as ações contemplem os movimentos do pensamento de redução do concreto ao abstrato e de ascensão do abstrato ao concreto.
\end{abstract}

Palavras-chave: Davýdov. Ensino de Matemática. Organização do ensino. Pensamento teórico. Teoria do Ensino Desenvolvimental.

\begin{abstract}
The current article presents the doctorate research track which had as object the organization of Mathematics teaching. The focus issue of our investigation resulted in: what are the contributions of the Theory of Developmental Teaching to the organization of the teaching of area and the perimeter concepts in the initial years of Elementary School? The discussions are based in the Theory of Developmental Teaching, which support the development of a didactic experiment, with the proposition of an assignment of study, and the analysis of its results. The evaluation of the experiment outlines the formation process of analysis capabilities, planning and reflection, components of the theoretical thinking. It was found, in the analysis of the experiment, that the thinking in theoretical level can be implemented through the assignment of study, when the actions consider the thinking movements from concrete reduction to abstract and the rise from the abstract to the concrete.
\end{abstract}

Keywords: Davýdov. Mathematics teaching. Organization of teaching. Theoretical thinking. Theory of Developmental Teaching.

Para citar - (ABNT NBR 6023:2018)

SERCONEK, Giselma Cecilia; SFORNI, Marta Sueli de Faria. Teoria do Ensino Desenvolvimental e a organização do ensino dos conceitos de área e de perímetro nos anos iniciais do ensino fundamental. Eccos Revista Científica, São Paulo, n. 56, p. 1-16, e8832, jan./mar. 2021. Disponível em: https://doi.org/10.5585/eccos.n56.8832. 


\section{Introdução}

Este texto resulta de pesquisa de doutorado e tem como objetivo apresentar nossa trajetória teórico-metodológica de investigação e análise dos resultados produzidos, a fim de trazermos à discussão contribuições da Teoria do Ensino Desenvolvimental para a organização do ensino. Nosso trabalho teve como eixo condutor de investigação o seguinte problema: quais as contribuições da Teoria do Ensino Desenvolvimental para a organização do ensino dos conceitos de área e de perímetro nos anos iniciais do Ensino Fundamental? Articulado a esse problema, definimos como objetivo geral analisar tais contribuições por meio de estudos teóricos e experimento didático.

O problema de investigação surgiu de nossa experiência profissional e acadêmica. Como professora da educação básica durante vinte anos e, atualmente, como professora de prática de ensino no curso de Pedagogia, testificamos as agruras vividas por aqueles que aprendem e aqueles que ensinam a Matemática: baixa proficiência dos estudantes, retenção na série, medos, inseguranças, fugas. As dificuldades, nessa área do conhecimento, se confirmam nas avaliações externas analisadas: PISA (2012, 2015), SAEP (2013) e SAEB (2015) ${ }^{1}$.

Como participante do grupo $\mathrm{GEPAE}^{2}$, nos dedicamos aos estudos de importantes estudiosos russos, entre eles aos de Davýdov, que possuem investigações teórico-práticas acerca do ensino desenvolvimental. Esse tipo de ensino visa a promover a aprendizagem do estudante em nível teórico, a fim de desenvolver suas capacidades cognitivo-afetivas, que o habilitam a atuar teórica e autonomamente. Além dos princípios gerais que embasam a organização do ensino, depreendemos desses estudos princípios específicos do ensino da Matemática, ciência que é foco em nosso trabalho.

Para respondermos à nossa problemática e atingirmos o objetivo proposto, fundamentamos nossa investigação na Teoria Histórico-Cultural e teorias que dela se desdobram: Teoria da Atividade e Teoria do Ensino Desenvolvimental. Com base nessas teorias realizamos uma pesquisa teórico-prática, culminando com o desenvolvimento e análise de um experimento didático.

No primeiro momento, investigamos o que vem sendo aprendido e ensinado em Matemática, assim como a estrutura epistemológica dessa ciência. Na sequência, investigamos o processo psíquico de formação do conceito e do pensamento sob a lógica

\footnotetext{
${ }^{1}$ PISA - Programa Internacional de Avaliação de Estudantes. Trata-se de uma avaliação comparada, aplicada a estudantes na faixa dos 15 anos, em vários países. SAEP - Sistema de Avaliação da Educação Básica do Paraná. Tem como objetivo obter informações do desempenho escolar (testes) dos alunos do $6^{\circ}$ ano e dos fatores que se associam a esse desempenho (questionários). SAEB - Sistema de Avaliação da Educação Básica. A Prova Brasil, que faz parte desse Sistema, tem por objetivo avaliar o desempenho dos alunos do $5^{\circ}$ ano e acompanhar a evolução de cada escola. 
formal e a dialética, bem como o respectivo tipo de pensamento desenvolvido: o empírico e o teórico. O momento seguinte é constituído por estudo da Teoria do Ensino Desenvolvimental, com destaque aos princípios fundamentais que orientam a organização do ensino. Os resultados dos estudos empreendidos tornaram-se subsídio teórico-metodológico para o desenvolvimento e análise do experimento didático, etapa final do trabalho.

\section{A Matemática como disciplina escolar}

No ambiente escolar, em todos os níveis de ensino, a Matemática é considerada uma disciplina com conceitos difíceis de serem aprendidos e ensinados. Há, paralelamente, uma ideia de naturalização e aceitação dessa dificuldade, considerando-se que alguns sujeitos nasceram com uma predisposição biológica para a compreensão dos fenômenos matemáticos e de que a outros, a maioria, a natureza não privilegiou com o talento para lidar com os números. No entanto, como afirma Ilyenkov (2007), os problemas enfrentados na aprendizagem dos conceitos matemáticos não estão correlacionados a essa predisposição natural, mas à organização didática de seu ensino, que possui um programa baseado em concepções equivocadas, por exemplo: de concreto como aquilo que é empírico, ou seja, sensível aos sentidos dos estudantes; de abstrato como manipulação verbal de terminologias e definições; da relação existente entre o geral e o particular, como movimento unilateral, entre outros equívocos.

Assim como Ilienkov, visualizamos possibilidades de superação da visão reacionária de organização didática por meio da pesquisa desenvolvida por D.B. Elkonin e de V.V. Davýdov, nas décadas entre 1960 e 1980, na Rússia, que deu origem ao Sistema ElkoninDavýdov de ensino. Esse sistema caracteriza-se por uma compreensão lógico-dialética da formação do conceito e do pensamento, que supera, por incorporação, a lógica formal.

$\mathrm{Na}$ escola, analisamos os conteúdos e os objetivos dos currículos de Matemática e observamos que sua estrutura organizacional é orientada pela lógica formal, revelada no modus operandi do ensino desse conhecimento. Os currículos analisados correspondem ao currículo geral de Matemática do $1^{\circ}$ ao $5^{\circ}$ ano e ao específico do $4^{\circ}$ ano, por ser a série na qual realizamos nosso experimento didático. Eles encontram-se no documento intitulado Currículo da Educação Infantil e Anos Iniciais do Ensino Fundamental, de 2012, do Município X ${ }^{3}$.

${ }^{3}$ Referimo-nos ao município paranaense selecionado para nossas investigações como Município X para preservarmos sua identidade. 
A apresentação dos conteúdos e seus respectivos objetivos no currículo caracteriza-se por uma natureza estática, fragmentada e isolada, que leva a ações docentes e discentes que desconsideram os nexos, as contradições e os movimentos inerentes a todo conhecimento teórico. Na estrutura dos conteúdos, por exemplo, subdivide-se os conceitos matemáticos em: eixos, conteúdos estruturantes e conteúdos específicos. Com base nisso, podemos inferir a ausência de interconexão entre os sistemas conceituais de grandeza, aritmética, geometria e álgebra. Em relação aos objetivos, observamos predominância de ações marcadas pelo empirismo, com a indicação de ações de identificar, reconhecer e/ou comparar aspectos acessórios do objeto de estudo, a fim de verificar sua utilidade imediata no cotidiano. Exemplo: "Reconhecer o decímetro, centímetro e milímetro como uma fração do metro para perceber a importância desse fracionamento em diversas situações diárias” (MUNICÍPIO X, 2012).

No âmbito da didática, a organização do ensino sob a lógica formal presente nas escolas torna-se um fator cerceador da promoção da aprendizagem e desenvolvimento do estudante. Primeiro porque, como Vygotsky (1931) comprovou em seus experimentos, os conceitos situam-se em um sistema conceitual e nesse sistema há uma relação de reciprocidade no processo formativo dos conceitos. Segundo porque tal sistema, afirma Davýdov (1982), possui um conceito nuclear que lhe dá origem e transpassa por todos os outros conceitos, interligando-os.

Na Matemática, o caráter sistêmico e de nuclearidade, segundo Davýdov (1982), é identificado em sua constituição lógico-histórica resultante da organização social dos homens. Em função da necessidade de controle, representação e comunicação das ideias matemáticas, o conceito nuclear matemático é o de grandeza que se inter-relaciona com os sistemas conceituais de geometria, álgebra e aritmética. Do conceito geral de grandeza deduzem-se os conceitos particulares de números, os quais tornam-se suas manifestações quantitativas para controle. Com base nessas relações entre o geral e o particular, o autor conclui que a grandeza se torna o conceito nuclear do processo de formação do pensamento teórico da Matemática.

Conforme essa perspectiva, para que o ensino supere a tendência empirista de conhecimento dos conceitos matemáticos, a escola deve organizar o ensino de modo que possibilite, aos estudantes, realizar abstrações e generalizações dos aspectos nucleares e essenciais do objeto em sua origem lógico-histórica, desde os anos iniciais da escolaridade. 


\section{A formação do conceito e do pensamento sob a lógica formal e a lógica dialética}

Além de considerar o caráter sistêmico e nuclear dos conceitos, para a organização do ensino é necessário compreender e considerar como ocorrem o processo de sua formação e sua relação com o desenvolvimento dos tipos de pensamento: o empírico e o teórico. Esses fenômenos psíquicos ocorrem nas interações que o professor promove entre o aluno e o conhecimento, com o emprego de instrumentos e símbolos culturais cada vez mais complexos. A apropriação ativa dos materiais culturais transforma qualitativamente os processos psíquicos elementares em processos psíquicos volitivos superiores (percepção, memória, atenção voluntária, memória lógica, pensamento teórico, entre outros) de comportamento humano em um movimento ascendente.

O mundo, declara Kopnin (1978), pode ser conhecido e pensado sob a lógica formal e sob a lógica dialética, que conduzem a concepções distintas dos fenômenos estudados. Ambas as teorias do conhecimento possuem leis e métodos de análise legítimos e relevantes, porém a lógica dialética tem como finalidade descobrir as leis gerais do conhecimento e sua relação com a realidade objetiva, enquanto a lógica formal volta-se a seus aspectos particulares e aparentes.

A formação de conceitos sob a lógica formal caracteriza-se pela identificação e comparação dos atributos externos de um objeto, com a identificação de semelhanças ou diferenças que se tornam referência para associação e classificação em grupos conceituais. Assim, afirma Davýdov (1982), ocorrem as ações de abstração e generalização que caminham do singular para o geral, classificando os conceitos de modo harmônico e concordante. Os conceitos formados por meio do isolamento e hierarquização dos atributos externos e/ou periféricos do objeto de estudo promovem o conhecimento e o pensamento do tipo empírico, resultado de um esquematismo formal. Esse processo de generalização não considera a gênese e o contexto do conceito, nem seus nexos internos e contraditórios.

Essa forma de apreensão do real, apesar de válida, tem seus limites no processo de conhecimento, como sustenta Ilienkov (1982). Para o autor, o conhecimento científico do objeto real não pode nascer dele mesmo, já que a imagem que o representa é caótica por não incluir suas múltiplas determinações. O método de conhecimento da lógica formal transforma o particular em instância do real, a soma das partes em totalidade.

O objeto de estudo e suas representações possuem, em seu conteúdo, relações internas e externas que a experiência sensualista não alcança. Assim, o conceito advindo dessa lógica de conhecimento reduz-se à vinculação entre as palavras e os objetos por meio de descrições e 
definições formais que demarcam suas propriedades e a classe à qual pertence. Não possibilita, também, a formação de conceitos em nível teórico e mantém o sujeito no que Vigotski (1931) denomina de plano do pensamento concreto-factual ou pensamento empírico.

Em uma perspectiva lógico-dialética, a formação do conceito pressupõe a análise e abstração dos atributos essenciais do objeto de estudo, de seus nexos externos e internos. Assim, o sistema de abstrações revela o objeto em sua universalidade e concreticidade, base para a compreensão da lei geral do conceito, para a generalização dedutiva-abstrata. Por essa via, declara Menchinskaia (1969), o estudante é conduzido ao nível do concreto pensado em sua origem, suas inter-relações e sua unidade, ou seja, ao pensamento teórico.

O pensamento do tipo teórico implica a compreensão do objeto em sua totalidade e ações mentais que permitem operar com os conceitos formulados acerca desse objeto. Desenvolve-se, assim, um "modo geral de ação" que possibilita ao estudante resolver distintas tarefas particulares, as quais envolvem um mesmo princípio, fazendo uso do conteúdo do conceito.

Repensar a organização do ensino requer clareza dos tipos de pensamento que a lógica formal e a lógica dialética de conhecimento promovem no estudante: o pensamento do tipo empírico e o pensamento do tipo teórico. Sem esquecer que o desenvolvimento do pensamento teórico é alcançado ao incorporar e superar o pensamento do tipo empírico.

Para Davídov e Márkova (1987), um equívoco comum nas escolas é a priorização das ações empíricas por um longo período da escolaridade e a ausência do engendramento de condições para o desenvolvimento das capacidades cognitivas próprias do pensamento teórico. Por essa razão, os autores consideram necessária uma reorganização do ensino das disciplinas, com revisão dos conteúdos e dos modos de ensino para a assimilação de conceitos científicos e o desenvolvimento do pensamento teórico, a partir dos anos iniciais da escola.

\section{Princípios da Teoria do Ensino Desenvolvimental para a organização do ensino}

A reorganização do ensino das disciplinas escolares exige de nós, profissionais da educação, repensar conteúdos e procedimentos de ensino. Dos estudos realizados sobre a Teoria do Ensino Desenvolvimental, destacamos princípios teórico-metodológicos que podem orientar um modo geral de organização do ensino promotor de aprendizagem e de desenvolvimento psíquico. A organização do ensino desenvolvimental dispõe o processo de assimilação do conteúdo escolar sob a forma de "tarefas de estudo", que estabelecem a relação entre o objetivo da ação e as condições para alcançá-lo. A "tarefa de estudo" é 
constituída por ações de estudo, que são as transformações objetivas e mentais realizadas pelo estudante. As ações de estudo, por sua vez, são desenvolvidas por "tarefas particulares" objetivadas em operações de estudo correspondentes às condições dadas (DAVIDOV, 1999).

Davídov (1988) propõe a realização de seis ações de estudo fundamentais para que o estudante alcance os objetivos pré-estabelecidos para a tarefa de estudo:

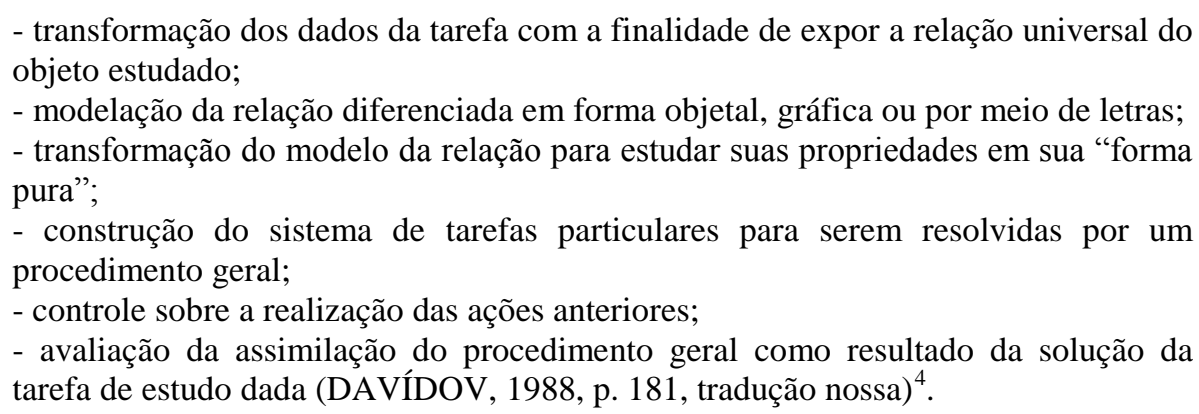

Na organização da tarefa de estudo, tendo em vista o ensino desenvolvimental, faz-se indispensável considerar o princípio do caráter social de desenvolvimento cognitivo do homem, que se refere à interiorização dos signos, que são veiculados no plano social por meio das relações interpsíquicas que a criança estabelece com o adulto. Inferimos desse princípio a função primordial da escola de converter os conhecimentos e as habilidades sociais externas em aptidões e conhecimentos de sua individualidade.

Os princípios do caráter ativo, do caráter problematizador e da unidade afetividadecognição articulam-se na tarefa de estudo, promovendo a atuação do estudante dirigida pela necessidade e pelo motivo gerados pela situação desencadeadora de estudo. $\mathrm{O}$ aspecto ativo tem por objetivo propiciar condições para que o aluno forme e generalize conceitos, coloqueos em uso, aprenda a estudar, aprenda a pensar teoricamente. Estar ativo não é simplesmente agir empiricamente, mas realizar conscientemente ações que podem ser materiais, verbais ou mentais. Para Talizina (2000, p.221, tradução nossa), as ações se convertem em mecanismos psicológicos de aprendizagem, pois "participam como o elo condutor e o meio para a formação dos conceitos. Sem elas, o conceito não pode ser assimilado nem utilizado, posteriormente, na resolução de problemas",

A situação-problema apresentada na tarefa de estudo exige do estudante plena atividade quando lhe solicita a análise das condições da situação, dos modos de ação que

\footnotetext{
${ }^{4}$ No texto original, lê-se: "transformación de los datos de la tarea con el fin de poner al descubierto la relación universal del objeto estudiado; modelación de la relación diferenciada en forma objetal, gráfica o por medio de las letras; transformación del modelo de la relación para estudiar sus propiedades en "forma pura"; construcción del sistema de tareas particulares a resolver por un procedimiento general; control sobre el cumplimiento de las acciones anteriores; evaluación de la asimilación del procedimiento general como resultado de la solución de la tarea de estudio dada" (DAVÍDOV, 1988, p. 181).

${ }^{5}$ No texto original, lê-se: "participan como el eslabón conductor y como el medio para la formación de los conceptos. Sin ellas, el concepto no puede ser asimilado ni utilizado posteriormente en la resolución de problemas" (TALIZINA, 2000, p.221)
} 
possuem e dos que lhes faltam, a fim de encontrar uma solução para ela. Então, com base no resultado dessa análise, o estudante formula planos de ação. Durante e/ou ao final da tarefa, o estudante controla e avalia não somente os resultados de suas ações, assim como o modo geral de ação que tomou como princípio orientador. Segundo Davídov (1988), os estudos de M. Skatkin atestam que a assimilação dos conhecimentos teóricos não se dá de forma passiva, pronta, mas como resultado da participação ativa do aluno em tarefas cognitivas. Para isso, a escola pode usar tarefas cognitivas problematizadoras do conhecimento como meio de tornar o estudante copartícipe do pensamento científico.

Para a formação do conceito científico e desenvolvimento do pensamento teórico, há que se propor tarefas que encetam o princípio da generalização que articula em si o geral e o particular como um processo dinâmico, ininterrupto e articulado. O processo de generalização de conceitos envolve uma série de elementos interconexos que se influenciam em um movimento geral-particular e particular-geral, com avanços guiados pela linguagem. A organização do ensino requer, portanto, a inclusão de ações e operações que reproduzam o conceito em sua universalidade em um movimento de ir e vir entre aspectos gerais e particulares; são procedimentos reveladores da essência do objeto real. A forma como o estudante se relaciona com o objeto e elabora suas generalizações conceituais (elementares ou teóricas) é determinante do tipo de pensamento (empírico ou teórico).

A generalização de conceitos expressa as interconexões entre o geral e o particular, o intrínseco e o extrínseco. Por conseguinte, a tarefa de estudo "requer o uso consciente e circunstanciado das características dialéticas dos conceitos teóricos" em intervenções ativas e problematizadoras, o que leva o aluno a assimilar a essência dos conteúdos de uma disciplina (DAVÝDOV, 1982, p.399, tradução nossa) ${ }^{6}$.

Toda ciência possui um conceito que lhe é nuclear, ou seja, que integra uma base conceitual generalizada do objeto em sua natureza. O conceito nuclear de uma ciência revela sua gênese, relações, contradições e complementações, que constituem o conhecimento em sua essencialidade. A utilização do princípio do conceito nuclear de uma ciência como ferramenta de assimilação de conhecimentos teóricos, segundo Talizina (2000), bem como das habilidades cognitivas a ele correspondente, conduz a um modo de organização do ensino voltada à formação de capacidades gerais de ação. Esse tipo de capacidade permite, ao estudante, compreender e utilizar novos conceitos que possuem a mesma base conceitual.

${ }^{6}$ No original lê-se: "requiere el empleo consciente y circunstanciado de las características dialécticas de los conceptos teóricos” (DAVÝDOV, 1982, p.399). 
Da apreensão da relação universal do objeto elaboram-se as abstrações e as generalizações iniciais sobre ele. A essência das relações internas do objeto pode ser modelada, ou seja, representada na forma objetal, gráfica ou literal, que substitui simbolicamente o conceito nuclear do objeto. Assim, a relação universal contida no modelo orienta um modo geral de ação ao tornar-se uma base teórica geral que permite resolver toda uma classe de problemas com os mesmos princípios. Temos aqui o princípio da modelação como reflexo das relações essenciais do objeto que orienta o modo geral de ação.

Um importante princípio a ser considerado na organização da tarefa, pelo professor, é do duplo movimento do pensamento: de redução do concreto ao abstrato e ascensão do abstrato ao concreto. No primeiro movimento, por meio da análise e do encontro do que é nuclear do objeto, reduzem-se suas diferenças e destaca-se sua essência. As abstrações iniciais expressam as relações depreendidas do objeto e constituem-se sínteses sobre ele (redução), mesmo que provisórias. A partir dos elementos teóricos da síntese, o estudante planeja suas ações para a resolução de novas tarefas particulares e monitora seus resultados. Nesse segundo movimento, o pensamento ascende do abstrato ao concreto, do geral ao particular, no qual se forma o pensamento teórico capaz de apreender a realidade em sua complexidade.

Para apreender um conceito em sua totalidade, a tarefa de estudo implica estabelecer uma relação entre os aspectos lógico e o histórico do objeto ou fenômeno de estudo. $\mathrm{Na}$ tarefa, o estudante reproduz a lógica interna que constituiu o conhecimento historicamente produzido por uma coletividade. A apreensão dessa verdade objetiva e real, como coloca Kopnin (1978), subentende o movimento do pensamento apoiado em seus aspectos históricos (realidade) e lógicos (teóricos) que refletem a logicidade dos nexos internos da realidade, libertos das casualidades. Segundo Rosental e Straks (1958), conhecer um objeto é apreendêlo como resultado de um desenvolvimento dialético entre o universal, o particular e o singular, e não como um produto acabado.

\section{Um experimento didático com os conceitos de área e de perímetro}

Ao longo de nossa investigação transitamos pelos estudos referentes à ciência Matemática, aos fundamentos do processo de formação do conceito e do pensamento teórico e aos princípios da Teoria do Ensino Desenvolvimental. Com base neles, sistematizamos e realizamos um experimento didático, cujo objetivo foi analisar as contribuições da Teoria do Ensino Desenvolvimental para a organização do ensino dos conceitos de área e de perímetro nos anos iniciais do Ensino Fundamental. O desenvolvimento de um experimento foi um 
desafio teórico-metodológico de proposição de um modo geral de organização de ensino, a partir dos princípios e conceitos estudados.

Em nosso experimento, consideramos os conceitos de área e de perímetro como um exemplo particular do conteúdo nuclear da Matemática - grandeza - a fim de levar o aluno a uma concepção circunstanciada e válida desses conceitos. Com base no experimento com esses conceitos específicos, foi possível deduzir princípios gerais para a organização do ensino próprio dessa ciência, em correspondência com seu plano epistemológico. $\mathrm{O}$ experimento foi realizado em uma turma do $4^{\circ}$ ano do Ensino Fundamental, em uma escola municipal paranaense, no período de contraturno, no qual eram oferecidas oficinas variadas, incluindo a de Matemática. A metodologia e os procedimentos adotados no experimento didático obedeceram às normas e aos princípios éticos de pesquisas com seres humanos, mediante aprovação do conselho de ética da instituição a qual está vinculada a pesquisa.

Estruturamos o experimento na forma de tarefa de estudo, conforme anunciado por Davídov (1988). A tarefa de estudo foi desenvolvida por meio de uma sequência de nove tarefas particulares, cuja resolução caracterizou-se por ações conjuntas, colaborativas e coordenadas. Por meio delas, revelaram-se as relações universais dos conceitos de área e de perímetro, com a formulação dos conceitos científicos e de suas ações correspondentes.

A capacidade para apreender o sentido nuclear de um conceito e com ele operar está associada e subordinada às capacidades de análise, plano interior de ação e de reflexão substanciais (teóricas). Essas capacidades são, conforme Sforni (2004, p.116), componentes essenciais da consciência e do pensamento teórico. É essa qualidade de pensamento que, posteriormente, desempenha "influência essencial sobre o desenvolvimento de todas as outras funções, permitindo ao sujeito certa autonomia na apropriação e produção de novos conhecimentos".

Davídov e Slobódchikov (1991) asseveram que a base da formação do pensamento teórico nos alunos de pouca idade é a realização sistemática de tarefas de estudo coletivas, as quais pressupõem o desenvolvimento, nas crianças, de capacidades, como:

a planificação (a habilidade para orientar-se corretamente na atividade conjunta e própria), a análise (a capacidade de diferenciar em seus conhecimentos e ações: o fundamental e o derivado, o principal e o secundário), a reflexão (a habilidade para passar do exame dos resultados de suas ações à explicação dos procedimentos mesmos de sua realização) (DAVÍDOV; SLOBÓDCHIKOV,1991, s/p, grifos dos autores). 
As tarefas de estudo foram organizadas de modo a envolver essas capacidades substanciais e favorecer o uso consciente delas. Em conformidade com essas proposições, tomamos esses componentes como unidades conceituais de análise, com o objetivo de investigar a atividade de pensamento em fluxo, das primeiras às últimas ações de estudo.

Primeiramente, realizamos uma série de quatro tarefas particulares para pôr em movimento o processo mental de redução do concreto ao abstrato. Com a intenção de gerar um motivo interior nos alunos, iniciamos com uma situação-problema desencadeadora da tarefa de estudo que contemplou a necessidade social do conceito: medir a área e o perímetro de uma superfície e comunicar os resultados. A situação desencadeadora e as tarefas particulares que a seguiram requeriam do aluno operações de reprodução da relação lógicohistórica das medidas de área e de perímetro de figuras poligonais retangulares e quadradas.

Propusemos, então, o estudo dos conceitos de área e de perímetro por meio da análise das propriedades essenciais contidas em sua forma concreta (superfície de um isopor quadrado) e dos meios para medi-la, a fim de conduzir os estudantes à revelação da base universal dos conceitos de área e de perímetro. Esse objetivo foi alcançado com a abstração e a generalização das relações essenciais de ambos os conceitos, até chegar à constituição do modelo de medição de área $(\mathrm{A}=a \times b)$ e de perímetro $(\mathrm{P}=\ell+\ell+\ell+\ell)$.

Todo o processo de análise foi realizado em grupo, em situações de discussão e argumentação intra e intergrupal, com registros dos procedimentos para paulatinamente se constituir a modelação dos conceitos. Na primeira tarefa, realizaram análise do objeto de estudo, utilizando medidas antropomórficas (escolheram o uso dos dedos das mãos). Tanto o processo como os resultados das medições não possibilitaram responder à situação-problema colocada, pois não obtiveram as medidas exatas do objeto. Nessa tarefa, o objetivo era dar início à reprodução da lógica interna do processo histórico de formação do conceito, com a composição do movimento do pensamento.

$\mathrm{Na}$ segunda tarefa, utilizaram unidades básicas de medida (unidades quadradas de E.V.A) que possibilitavam abstrair a propriedade bidimensional de área, promovendo o início do desvelamento de sua essência. Na terceira tarefa, utilizaram um quadrado de E.V.A. de $1 \mathrm{~cm}^{2}$ como unidade básica de medida e a régua para estabelecerem relações entre a unidade básica e o instrumento convencional de medida e entre eles e o objeto a ser medido. $\mathrm{Na}$ sequência de cada tarefa particular, os alunos registraram os procedimentos em forma gráfica e de letras para constituir o processo de modelação do conceito. 
Por meio dessas tarefas particulares, propiciou-se o desenvolvimento das duas primeiras ações de estudo davydovianas de análise e modelação, nas quais os estudantes realizaram o caminho lógico-histórico de constituição desse conhecimento de modo ativo, descobrindo sua essência, a lei que o rege e o seu modelo universal.

Figura 1 - Análise da propriedade bidimensional

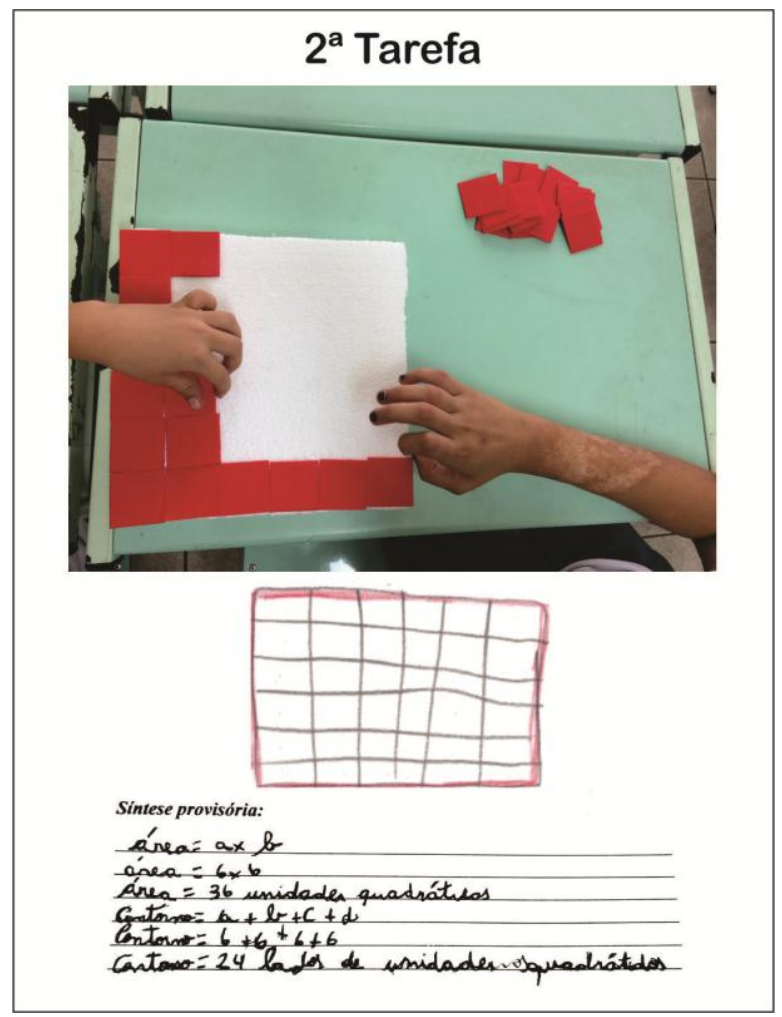

Fonte: SERCONEK, 2018
Figura 2 - Etapa final de modelação

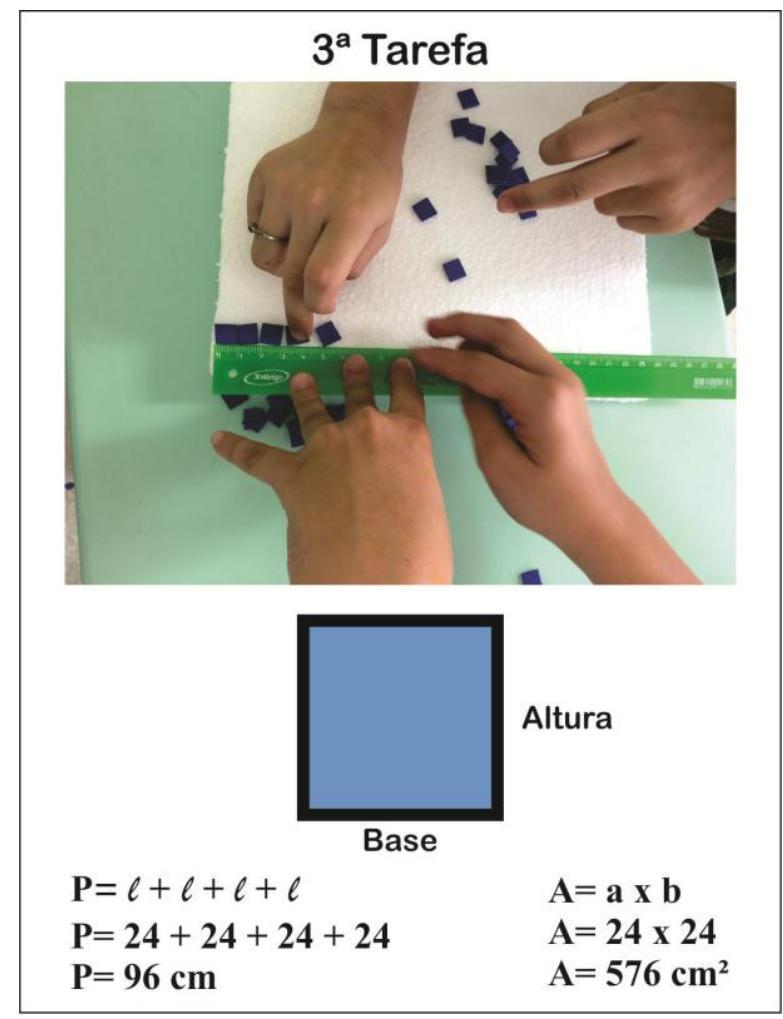

Fonte: SERCONEK, 2018

A quarta tarefa objetivou realizar a análise e a transformação do modelo para adequação à nova situação, conforme a terceira tarefa davydoviana. As contradições encontradas, pelos estudantes, entre o modelo e a nova situação-problema, criou a necessidade de buscar outros caminhos, que viabilizaram novas abstrações do material e ampliaram o domínio do modo geral de ação. O domínio teórico permitiu que se distanciassem das particularidades sensoriais do objeto, fixando-se no que é essencial e em seu modelo. "Nisso consiste, fundamentalmente, a tarefa da análise, ou seja, consiste na redução das diferenças existentes dentro do todo, com base naquilo que as gera, na sua essência" (DAVÍDOV, 1988, p.147). 
Figura 3 - Análise e transformação do modelo

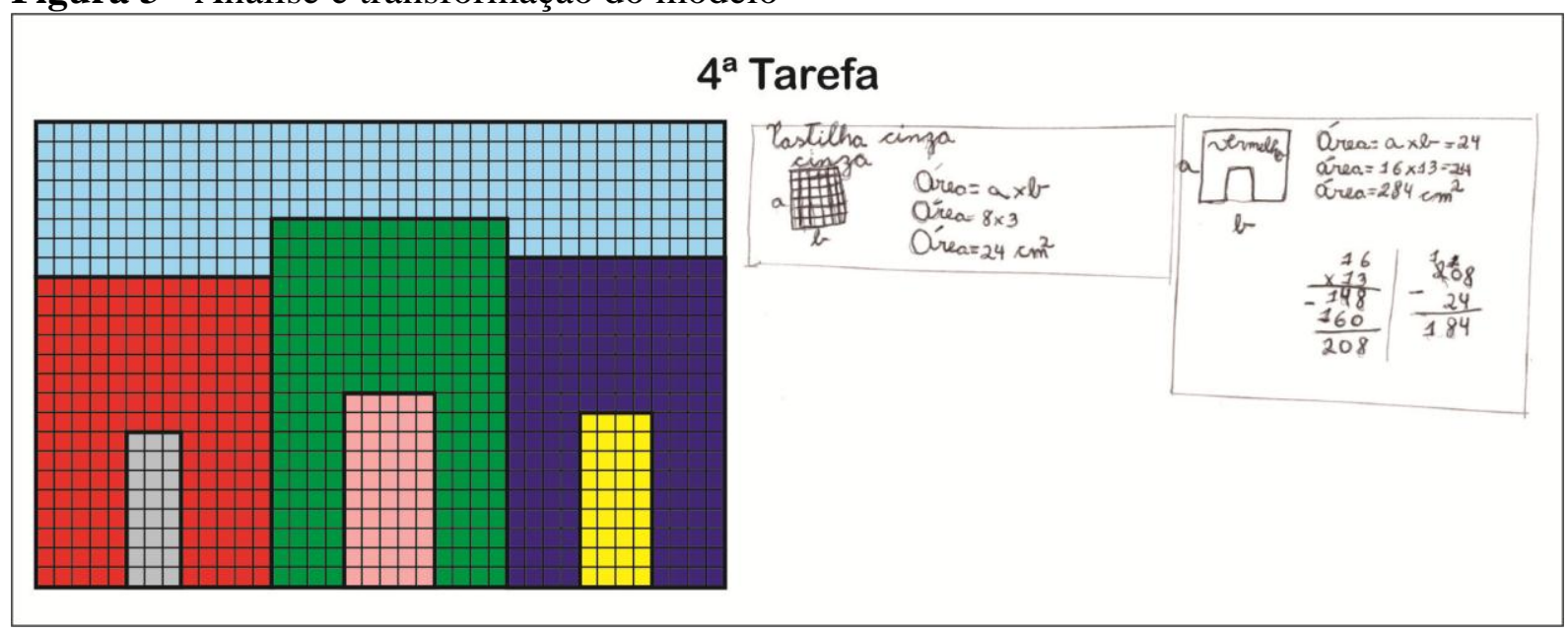

Fonte: SERCONEK, 2018.

O estudante, depois de abstrair e generalizar os conceitos científicos de área e de perímetro tomou-os como base para deduzir as relações particulares das tarefas dadas: planejar, monitorar e avaliar suas ações. Assim, a segunda parte da tarefa de estudo foi composta por cinco tarefas particulares, conforme as três últimas ações de estudo davydovianas, pondo em movimento o processo mental de ascensão do abstrato ao concreto.

A quinta, sexta e sétima tarefas particulares foram propostas com o objetivo de efetivar a quarta ação de estudo davydoviana, iniciando o processo de ascensão. Por meio da dedução, os estudantes resolveram as tarefas com base em procedimento geral de medição de área e de perímetro. Esse processo exigiu que eles fizessem um planejamento substancial de ações, apoiando-se, por exemplo, nas fórmulas matemáticas (modelos universais). Em uma tarefa de estudo, destaca Rubtsov (2003), o fundamental não é identificar e usar dados empíricos do objeto, mas compreender as condições da ação como uma orientação geral que pode ser aplicada a todo um sistema de tarefas que se fundam nos mesmos princípios.

A oitava e nona tarefas particulares foram propostas com o objetivo de efetivar a quinta e a sexta ações de estudo davydovianas, que correspondem, respectivamente, ao controle e monitoramento das ações e à avaliação de seus resultados, não para simples constatação, mas para o exame qualitativo e substantivo do resultado da assimilação. É por meio da reflexão que o estudante constata e compreende as razões de suas ações, em conformidade com as circunstâncias do problema dado em situação de ensino. Tal componente do pensamento caracteriza a tomada de consciência do modus operandi, isto é, a 
reconstrução e o monitoramento das ações no plano mental, em consonância com as condições de sua efetivação.

\section{Considerações finais}

Lembramos, aqui, que nosso objetivo não foi reproduzir "modelos" de tarefas davydovianas, como constam em livros didáticos pautados no Sistema Elkonin-Davýdov, mas desenvolver tarefas que contemplem princípios teóricos davydovianos. Assim, a experiência investigativa serviu de apoio para a construção de espaços reflexivos acerca do vir a ser de um ensino organizado sob a referida perspectiva. Desse modo, ao analisarmos os resultados de nosso experimento depreendemos contribuições formativas da proposta davydoviana de ensino e também os limites ao realizá-la em contexto brasileiro.

Os limites identificados não dizem respeito à pertinência da proposta apresentada por Davýdov, mas àquilo que a prática, em sua singularidade, revela acerca das condições objetivas da escolarização no contexto brasileiro: excesso de alunos em sala de aula; a ausência de atitudes de estudos, principalmente em ações coletivas; ausência do domínio de conceitos, que compõem o sistema de conceitos, requeridos no processo de generalização; a politomia conceitual existente no currículo dessa área de conhecimento, entre outros.

Podemos destacar a superação dos limites do pensamento empírico discursivo e o desenvolvimento do pensamento teórico pelos estudantes como contribuições evidenciadas na: capacidade de análise substantiva do objeto, por meio de ações objetais e verbaisdiscursivas pautadas em conceitos científicos; capacidade de síntese observada no processo de modelação e de sua transformação; tomada de consciência do conteúdo do conceito ao analisá-lo e utilizá-lo; capacidade de planejamento substancial de operações apoiadas no modelo; reflexão substancial observada no controle e avaliação das próprias ações.

Assim, ao retomar a pergunta que nos guiou, é possível anunciar que nossa experiência singular de organização do ensino dos conceitos de área e de perímetro, conforme os princípios davydovianos, dentro dos limites e das condições dadas, contribuiu para o processo de aprendizagem e de desenvolvimento do pensamento teórico dos estudantes, sujeitos da pesquisa, no que concerne à tarefa de estudo proposta. 


\section{Referências}

DAVÍDOV, Vasily Vassilyevich; MÁRKOVA, Aelita. El desarrollo del pensamiento en la edad escolar. In: SHUARE, Marta. (Comp.) La psicología evolutiva y pedagógica en la URSS - Antología. Moscú: Editorial Progreso, 1987.

DAVÍDOV, Vasily Vassilyevich. La enseãnza escolar y el desarrollo psiquico: investigación psicológica teórica y experimental. Moscu: Editorial Progreso, 1988.

DAVÍDOV, Vasily Vassilyevich; SLOBÓDCHIKOV, Víctor Ivanovitch. La enseñanza que desarrolla en la escuela del desarrollo. In: LIJMETS, J. L. La educación y la enseñanza: una mirada al futuro. Moscú: Progreso, 1991, p. 118-144.

DAVÍDOV, Vasily Vassilyevich. O que é a atividade de estudo. 9. При наличии диска CDROM с записями Каталога и текстов статей о развивающем обучении, пользователь защищен от утраты интересующей его информащии. Номер статьи по Каталогу: Ст. 158. Revista Escola Inicial, nº7, ano 1999. Tradução: Ermelinda Prestes.

DAVÝDOV, Vasily Vassilyevich. Tipos de generalización en la enseñanza. La Habana: Pueblo y Educación, 1982.

ILIENKOV. Évald Vasílievich. The dialectics of the abstract and the concrete in Marx's Capital. Moscow: Progress Publishers, 1982. Disponível em:

<https://www.marxists.org/archive/ilyenkov/works/abstract/index.htm>.

ILYENKOV. Évald Vasílievich. Our schools must teach how to think. Journal of Russian and East European Psychology, vol. 45, no. 4, July-August 2007, pp. 9-49. Tradução em inglês do texto russo "Shkola dolzhna uchit' myslit'!" in E.V. Ilyenkov, Shkola dolzhna uchit' myslit' (Moscow and Voronezh: Moskovskii psikhologo-sotsial'nyi institute and Izdatel'stvo IPO MODEK, 2002), pp. 6-55. Publicado com a permissão de Elena Evaldovna Illiesh.Traduzido por Stephen D. Shenfield.

KOPNIN, Pável Vassílievitch. A dialética como lógica e teoria do conhecimento. Rio de Janeiro: Editora Civilização Brasileira, 1978.

MENCHINSKAIA, Natalia Aleksandrovna. El pensamiento. In: LEONTIEV, Alexei Nikolaevich et al. Psicologia. México: Grijalbo, 1969.

MUNICÍPIO X. Secretaria Municipal de Educação - Currículo da Educação Infantil e Anos Iniciais do Ensino Fundamental. 2012.

ROSENTAL, Marc Moiseievich; STRAKS, G. M. Categorías del Materialismo Dialéctico. Tradução de Adolfo Sanchez Vazquez e Wenceslao Roces. México: Grijalbo, 1958.

RUBTSOV, Vitaly. A atividade de aprendizado e os problemas referentes à formação do pensamento teórico dos escolares. In: GARNIER, Catherine; BEDNARZ, Nadine; 
ULANOVSKAYA, Irina. Após Vygotsky e Piaget: perspectiva social e construtivista Escolas Russa e ocidental. Porto Alegre: Artes Médicas, 2003.

SERCONEK, Giselma Cecilia. Teoria do Ensino Desenvolvimental e aprendizagem: um experimento com conceitos de área e de perímetro $191 \mathrm{f}$. Tese (Doutorado em Educação) Universidade Estadual de Maringá, 2018.

SFORNI, Marta Sueli de Faria. Aprendizagem conceitual e organização do ensino: contribuições da teoria da atividade. Araraquara: JM Editora, 2004.

TALIZINA, Nina Fiodorovna. Manual de psicologia pedagógica. San Luis Potosí, México: Editorial Universitaria Potosina, 2000.

VYGOTSKY, Lev Semionovich. Obras escogidas. Tomo III, Moscú: Editorial Pedagógica, 1931. 